\title{
Téoros
}

Revue de recherche en tourisme

\section{Pour un organisme régional de gestion et de développement!}

\section{Jean Décarie}

Volume 9, numéro 1, mars 1990

Plans et politiques touristiques

URI : https://id.erudit.org/iderudit/1080290ar

DOI : https://doi.org/10.7202/1080290ar

Aller au sommaire du numéro

Éditeur(s)

Université du Québec à Montréal

ISSN

0712-8657 (imprimé)

1923-2705 (numérique)

Découvrir la revue

Citer cet article

Décarie, J. (1990). Pour un organisme régional de gestion et de développement! Téoros, 9(1), 29-30. https://doi.org/10.7202/1080290ar d'utilisation que vous pouvez consulter en ligne.

https://apropos.erudit.org/fr/usagers/politique-dutilisation/ 


\section{Pour un organisme régional de gestion et de développement!}

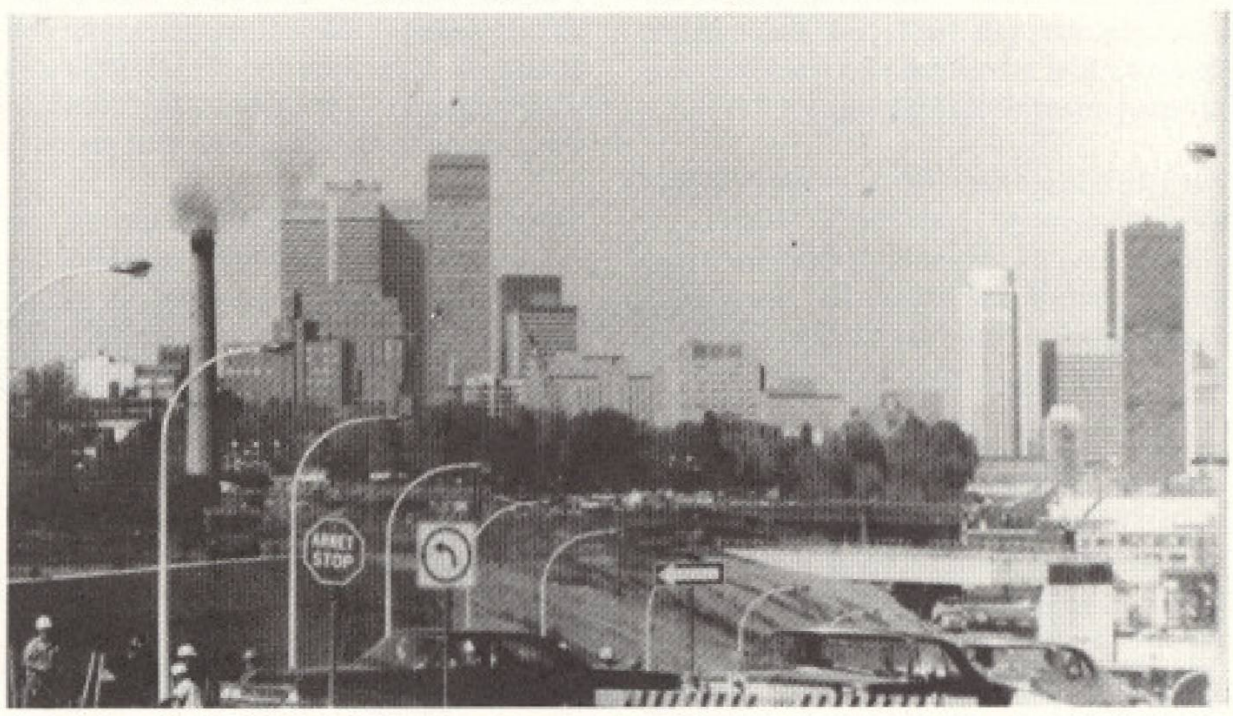

On annonçait récemment la création d'un organisme régional de gestion du transport collectif suite à un accord entre la S.T.C.U.M., la S.T.R.S.M. et la Société de Transport de Laval.

Cet ajustement administratif tardif à une réalité métropolitaine depuis longtemps évidente et criante permet de ne pas désespérer complètement des pouvoirs publics et s'ajoute à cette longue liste de révolutions politico-administratives qui auront marqué la planète en cette année 1989 faste et prédestinée.

Il reste seulement à espérer qu"il ne faudra pas attendre 2089 pour voir la mise en place d'une telle structure régionale capable de gérer la ressource RÉCRÉOTOURISTIQUE exceptionnelle de Montréal qui se présente naturellement, dans sa géographie comme dans son histoire, dans son écologie comme dans son économie, à l'échelle de la grande région urbaine métropolitaine de Montréal.

La Communauté urbaine de Montréal, créée en 1969 , n'a jamais été un organisme vraiment régional dans son statut - inter plus que supra - municipal, ni dans son mandat qui ne fait qu'effleurer de l'intérieur - assainissement, patrimoine, pares régionaux -ledomaine des ressources; ni encore moins, dans son échelle, limitée à l'île de Montréal, même si celle-ci compte les deux tiers de la population métropolitaine mais faut-il le rappeler, le tiers de celle du Québec.

La question des parcs régionaux est révélatrice à cet égard. Même si dès 1970 la C.U.M. s'était vue dotée d'une compétence en matière de parcs à caractère intermunicipaux - et non régionaux - ce statut même la laissait à la merci du chantage des municipalités de banlieue qui refusèrent d'intégrer les seuls grands parcs métropolitains existants, ceux de la Ville de Montréal, dans la première esquisse du schéma d'aménagement en 1972.

Malgré les pressions du Regroupement pour la préservation des espaces verts pour un plan global de la C.U.M. comprenant tous les grands pares et équipements régionaux, il faudra attendre 1979 pour voir Québec amender la loi de la C.U.M. et débloquer 10.5 millions pour lui permettre d'acquérir les espaces naturels résiduels périphériques de la rivière des Prairies, depuis longtemps identifiés par l'évidence de leur potentiel menacé.

Mềme s'il ne s'agissait pas à proprement 
parler de parcs régionaux, le caractère naturel de ces espaces, leur appartenance aux grands espaces ressources régionaux, archipélagiens, a autorisé le glissement sémantiquevers le statut de parcs régionaux. Peut-être est-ce ce qui explique qu'il faudra attendre 10 autres années, un changement d'administration et d'orientation à la Ville de Montréal, le dépôt du schéma d'aménagement de la C.U.M. en 1986, et de vigoureuses audiences publiques sur les parcs régionaux en 1987, pour voir enfin le début de leur ouverture - en attendant leur aménagement encore à venir.

Au début des années ' 80 , le projet Archipel avait également contribué à la prise de conscience de l'importance des ressources environnementales régionales. Archipel $\mathrm{I}$, le grand projet d'aménagement hydraulique a fins multiples, premier du genre au monde en milieu urbain et à finalité sociale plutôt qu'économique, premier projet de planification environnementale intégrée et concertée au Québec, avait déjà fait ressortirl' l'unité profonde du système hydraulique et économique de l'Archipel et sa relation au système urbain - 1'un et l'autre réunis dans une régulation socio-spatiale proposée en vue de la production collective et consentie d'un environnement urbain bonifié.

Suite a l'échec de ce projet, par collusion entre le Secrétariat Archipel et HydroQuébec - et par collision entre celle-ci et le M.L.C.P., ce dernier, éveillé sur le coupà la richesse de $1^{\dagger}$ archipel et à la réalité urbaine, devait élaborer Archipel $\mathrm{I}_{\uparrow}$ le Parc National de l'Archipel, où les beaux restes surnageants au naufrage dans les eaux de l'archipel allaient être récupérés et organisés dans le cadre de la nouvelle politique des parcs urbains élaborée parallèlement en 1983 par ce ministère.

Le naturel et les élections revenant au galop, l'appellation Parc National de l'Archipel masquait mal et déformait, au nom de la Nature et de la Nation, les principes et les modalités novateurs d'une politique sophistiquée, à la fois urbaine et régionale, parfaitement adaptée à la réalité physico-spatiale comme socio-politique de l'environnement complexe d'une grande région urbaine postindustrielle comme celle de Montréal.

Ainsi, la définition du parc urbain régional proposee, désignait-elle les grands espaces naturels périphériques encadrant $1^{+}$agglomération, au premier chef les espaces bleus, les six plans d'eaux de l'archipel qui constituent l'enveloppe et $l^{\prime}$ 'element environnemental dominant de Montréal, aussi les collines boisées résiduelles - Rigaud, Oka, les montérégiennes.

Pour chacun de ces plans d'eau, un schéma préliminaire d'aménagement avaitétéconçu puis accepté par une table de concertation réunissant les municipalités et certains groupes riverains, table qui, dans un second temps, devait se transformeren une structure formelle de développement et de gestion de l'espace-ressource commun. Des hypothèses étaient également soumises pour une forme de fédération de ces sociétés des pares régionaux en vue d'une planification intégrée du système régional tout entier.

Hélas, toute cette lente et patiente mise en scène devait être interceptée et confisquée pour fins électorales partisanes, ce qui ne laissait d'autres choix au nouveau gouvernement que de mettre tout le projet au rancart-malgré les affinités évidentes qu'il présentait avec son discours sur le désinvestissement gouvernemental et l'appropriation concomitante par les groupes et les collectivités locales.

Certaines municipalités, comme Longueuil, Lachineet Montréal, ont repris à leurcompte quelques éléments du projet - le réseau vert en particulier-mais oeuvrent en orphelines dans l'attente d'un encadrement régional minimal, décentralisé, qui ne peut par définition venir que de Québec, sous forme d'une régie ou d'une société de développement, sur le modèle des agences de bassins françaises, ou des authorities et des conservancies américaines - la Metro Toronto and Regional Conservation Authority par exemple, plus près de nous. et pour piquer une fois de plus notre fierte nationale.

A cet égard, le débat constitutionnel actuel est peut-êtreaussi prometteur pour Montréal que pour Québec. On constate en effet que, dans 1'histoire, ce sont les gouvernements souverainistes ou fortement autonomistes qui ont le plus été enclin à décentraliser le pouvoir territorial, à créer des autorités régionales fortes dont, au contraire, les gouvernements provincialistes, se considérant eux-mêmes comme des administrations régionales face à Ottawa, ont toujours craint la concurrence...

Peut-être, espérons le toujours, le lac Meech et le lac St-Louis sont-ils des vases communiquants! 